\title{
Impact of COVID-19 on in-hospital cardiac arrest outcomes: An updated meta-analysis
}

\author{
Karol Bielski1,2®0, Katarzyna Makowska ${ }^{3}$, Adam Makowski ${ }^{3}$, Tomasz Kopiec ${ }^{3}$,

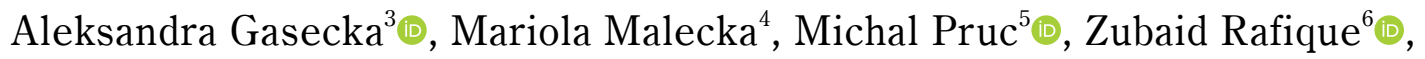 \\ Frank W. Peacock ${ }^{6}$, Andrea Denegri ${ }^{7}$, Lukasz Szarpak ${ }^{5,8}$ \\ ${ }^{1}$ Research Unit, Polonia University, Czestochowa, Poland \\ ${ }^{2}$ Provincial Emergency Medical Service Dispatcher, Warsaw, Poland \\ ${ }^{3}$ First Chair and Department of Cardiology, Medical University of Warsaw, Poland \\ ${ }^{4}$ Institute of Outcomes Research, Maria Sklodowska-Curie Medical Academy, Warsaw, Poland \\ ${ }^{5}$ Research Unit, Polish Society of Disaster Medicine, Warsaw, Poland \\ ${ }^{6}$ Henry JN Taub Department of Emergency Medicine, Baylor College of Medicine, Houston, TX, USA \\ ${ }^{7}$ Cardiology Division, Department of Biomedical, Metabolic and Neural Sciences, \\ University of Modena and Reggio Emilia, Policlinico di Modena, Modena, Italy \\ ${ }^{8}$ Research Unit, Maria Sklodowska-Curie Bialystok Oncology Center, Bialystok, Poland
}

\begin{abstract}
Background: The main purposes of this meta-analysis are to update the information about the impact of coronavirus disease 2019 (COVID-19) pandemic on outcomes of in-hospital cardiac arrest (IHCA) and to investigate the impact of being infected by by severe acute respiratory syndrome coronavirus type 2 (SARS-CoV-2) on IHCA outcomes.

Methods: The current meta-analysis is an update and follows the recommendations of Preferred Reporting Items for Systematic Reviews and Meta-Analyses (PRISMA).

Results: In analyses, pre-and intra-COVID-19 periods were observed for: shockable rhythms in $17.6 \%$ vs. $16.2 \%$ (odds ratio [OR]: $1.11 ; 95 \%$ confidence interval [CI]: 0.71-1.72; $p=0.65$ ), return of spontaneous circulation (ROSC) in 47.4\% vs. 44.0\% (OR: 1.36; 95\% CI: 0.90-2.07; $p=0.15$ ), 30-day mortality in $59.8 \%$ vs. $60.9 \%$ (OR: 0.95 ; $95 \%$ CI: $0.75-1.22 ; p=0.69$ ) and overall mortality $75.8 \%$ vs. $74.7 \%$ (OR: 0.80; 95\% CI: 0.49-1.28; $p=0.35$ ), respectively. In analyses, SARS-CoV-2 positive and negative patients were observed for: shockable rhythms in 9.6\% vs. $19.8 \%$ (OR: $0.51 ; 95 \%$ CI: 0.35-0.73; $p<0.001$ ), ROSC in 33.9\% vs. 52.1\% (OR: 0.47; 95\% CI: 0.30-0.73; $p<0.001$ ), 30-day mortality in $77.2 \%$ vs. $59.7 \%$ (OR: $2.08 ; 95 \%$ CI: $1.28-3.38 ; p=0.003$ ) and overall mortality in $94.9 \%$ vs. $76.7 \%$ (OR: 3.20; 95\% CI: 0.98-10.49; $p=0.05$ ), respectively.

Conclusions: Despite ROSC, 30-day and overall mortality rate were not statistically different in prevs. intra-COVID-19 periods, a lower incidence of ROSC and higher 20-day mortality rate were observed in SARS-CoV-2 (+) compared to SARS-CoV-2 (-) patients. (Cardiol J 2021; 28, 6: 816-824)

Key words: coronavirus disease 2019, COVID-19, SARS-CoV-2, pandemic, in-hospital cardiac arrest, cardiopulmonary resuscitation, outcome, meta-analysis
\end{abstract}

Address for correspondence: Lukasz Szarpak, Assoc Prof., PhD, DPH, DBA, MBA, LL.M., Maria Sklodowska-Curie Bialystok Oncology Center, ul. Ogrodowa 12, 15-027 Białystok, Poland, tel: +48 500186 225, e-mail: lukasz.szarpak@gmail.com

Received: 26.07.2020 Accepted: 2.08.2021 Early publication date: 17.12.2021

This article is available in open access under Creative Common Attribution-Non-Commercial-No Derivatives 4.0 International (CC BY-NC-ND 4.0) license, allowing to download articles and share them with others as long as they credit the authors and the publisher, but without permission to change them in any way or use them commercially. 


\section{Introduction}

The emergence of the world pandemic of severe acute respiratory syndrome coronavirus 2 (SARS-CoV-2) causing coronavirus disease 2019 (COVID-19) began in Wuhan, China in December 2019 [1-3]. In November 2021, respectively over 250 million confirmed cases and 5 million total deaths were reported globally [4].

The COVID-19 manifests itself as an asymptomatic or with a broad spectrum of features commonly regarding symptoms from the respiratory system, including even severe respiratory failure or death [5-7]. The most frequent symptoms involve: fever, cough, and dyspnea then myalgia or rhinorrhea [8-10]. In $14 \%$ of patients with pneumonia caused by SARS-CoV-2 hospitalization is required [5]. Subsequently in $15 \%$ of patients with initially severe outcomes of COVID-19 multi-organ failure or acute respiratory distress syndrome may occur $[6,11]$.

Nevertheless, the coexistence of chronic conditions from other systems such as: diabetes mellitus, hypertension, obstructive pulmonary disease, cardiovascular diseases or even obesity was related with worse predictions [8, 12-14].

To date a specific treatment has not been discovered [15]. However, the vaccinations may contribute to limiting the spread of SARS-CoV-2 [16, 17].

Research of the literature presented on the mortality rate in intensive care units may be higher than 35\% and according to this data, in-hospital cardiac arrest (IHCA) is described to be the main factor of this score $[18,19]$. The IHCA prior to and throughout the COVID-19 pandemic was higher in number, but indistinguishable in outcomes [20]. The survival rate in intra-hospital cardiac arrest was much higher than in out-of-hospital cardiac arrest (OHCA) [20]. Moreover, as pointed out by Shao et al. [18] the survival of patients with nonshockable rhythms is below $0.8 \%$. This is more disturbing, as cardiac arrests in COVID-19 patients occur much more often resulting from a respiratory failure mechanism than in patients with negative COVID-19 results [21, 22]. Because of the risk of SARS-CoV-2 infection, resuscitation of a patient with suspected or confirmed COVID-19 should be carried out using personal protective equipment (PPE) $[23,24]$. However, as shown by many studies $[25,26]$, the use of PPE for aerosol generating procedures (AGPs) may adversely affect the quality of chest compression. In order to improve the quality of the conducted resuscitation, Malysz et al. [27] compared two techniques of manual chest compression - demonstrating that paramedics wearing
PPE-AGP achieved better chest compression depth for over-the-head position compared to the standard chest position, however, over-the-head position resuscitation causes a lower full chest relaxation. It is therefore reasonable to use mechanical chest compression systems during resuscitation of a patient with COVID-19, both in pre-hospital and inpatient settings, which allow for standardization of chest compressions even during prolonged cardiopulmonary resuscitation [28].

The primary aim of this systematic review and meta-analysis is to assess the impact of the COVID-19 pandemic on outcomes due to IHCA. The secondary aim is to investigate the effect of SARS-CoV-2 infection of IHCA outcomes during the COVID-19 period.

\section{Methods}

The current systematic review and metaanalysis follows the recommendations of Preferred Reporting Items for Systematic Reviews and Meta-Analyses (PRISMA) guidelines for conducting and reporting its results [29]. A protocol of this meta-analysis has not been registered. Ethical approval and consent were waived because this study was a systematic review and meta-analysis of published literature. This meta-analysis is an update of the analysis previously published by the authors [20].

Methodology of systematic review and meta-analysis was described in a previous article [20]. The primary outcome was overall mortality. Secondary outcomes were return of spontaneous circulation (ROSC) as well as 30-day mortality.

The polled analysis was performed using RevMan 5.4 software (The Nordic Cochrane Center, Copenhagen, Denmark), using the odds ratio (OR) with $95 \%$ confidence interval (CI) for dichotomous outcomes, and the mean difference (MD) with $95 \%$ $\mathrm{CI}$ for continuous outcomes. When the continuous outcome was reported in a study as median, range, and interquartile range, means and standard deviations were estimated using the formula described by Hozo et al. [30]. A quantified heterogeneity in each analysis utilized the tau-squared and I-squared statistics. Heterogeneity was detected with the chi-squared test with $n-1$ degree of freedom, which was expressed as $\mathrm{I}^{2}$. Values of $\mathrm{I}^{2}>50 \%$ and $>75 \%$ were considered to indicate moderate and significant heterogeneity among studies, respectively. A random-effects model was used to pool study results independently of the p-value for heterogeneity or $\mathrm{I}^{2}$ [31]. All $\mathrm{p}$ values were two-tailed and considered significant if $<0.05$. 


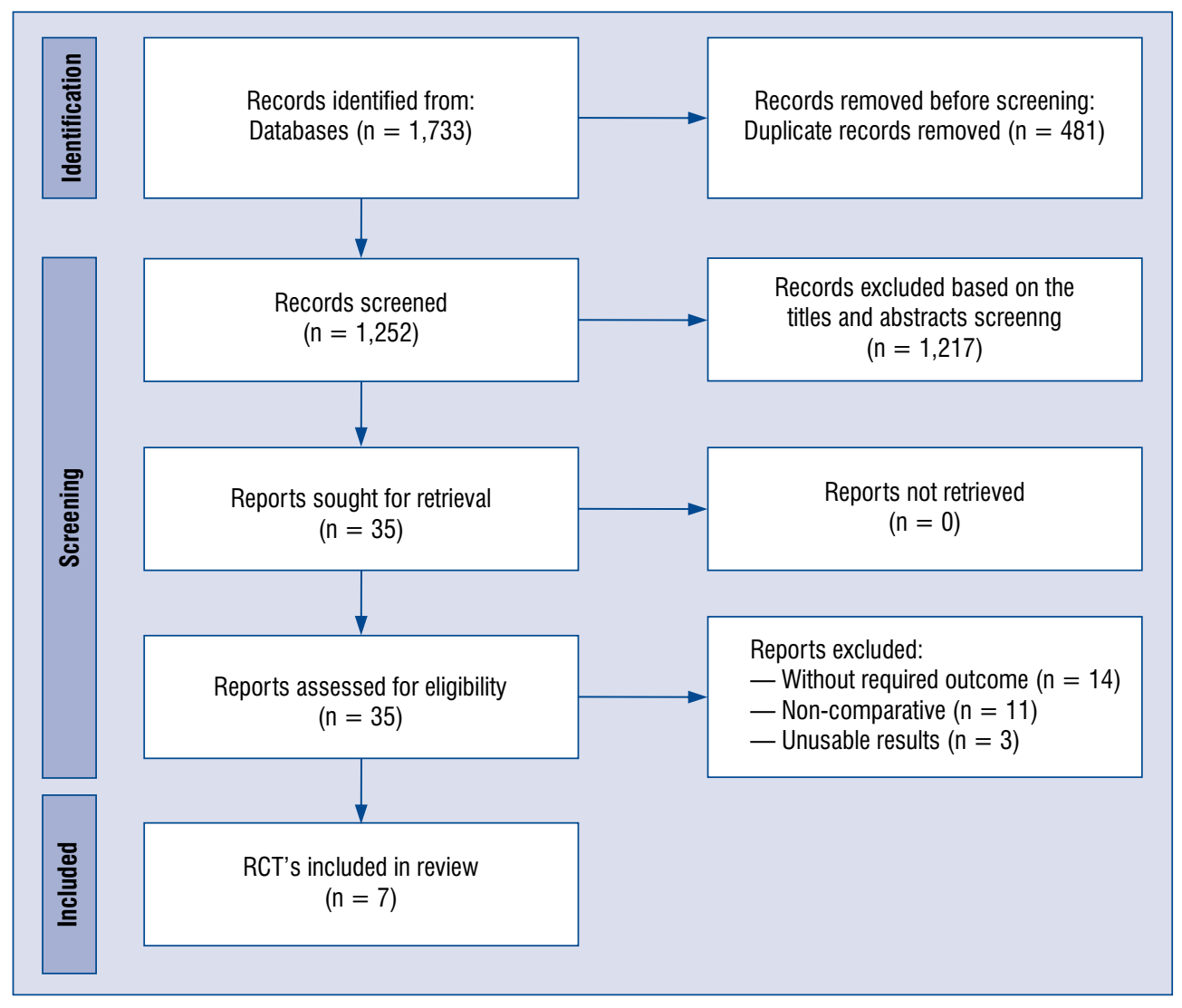

Figure 1. Flow diagram showing stages of the database search and study selection as per Preferred Reporting Items for Systematic Reviews and Meta-Analyses (PRISMA) guidelines; RCT — randomized controlled trials.

\section{Results}

Characteristics of studies included in the meta-analysis

A total of 1,733 articles were identified from the Medline (PubMed), Embase, Cochrane library, and a manual search as described above. After excluding duplicates, 1,252 articles remained. In the next step (screening the titles and abstracts of all retrieved articles), 1,217 articles were excluded. Thereafter, the full text was reviewed, and 28 studies were excluded because they contained pediatrics, which does not present a comparative group, report unusable results or were reviews or meta-analyses. Finally, 7 studies published from 2020 to 2021 including 3,049 IHCA patients were included in this meta-analysis (Fig. 1) [32-38]. Detailed characteristics of the studies included in the meta-analysis are presented in Table 1.

Five studies reported IHCA outcomes in prevs. intra-COVID-19 periods [32, 34-37] and 3 in COVID-19 period, dividing participants as SARS$\mathrm{CoV}-2$ positive vs. negative patients $[33,36,38]$.
Each study was then screened for risk of bias and methodological quality using the Cochrane Collaboration tool for assessing the risk of bias (Figs. 2, 3).

Analyses in pre- vs. intra-COVID-19 periods

Patient age in the pre- vs. intra-COVID-19 periods varied and amounted to $71.6 \pm 13.3$ vs. $69.9 \pm 14.4$ years, respectively (MD: $0.62 ; 95 \%$ CI: -0.71 to $1.95 ; \mathrm{p}=0.36$ ). Characteristics of patients with IHCA in pre vs. intra-COVID-19 periods and resuscitation process are presented in Table 2.

Shockable rhythms were observed in $17.6 \%$ of cases in the pre-COVID-19 period compared to $16.2 \%$ for the in COVID-19 period (OR: $1.11 ; 95 \%$ CI: $0.71-1.72 ; \mathrm{p}=0.65$ ).

Five studies reported ROSC in pre- vs. intra-COVID-19 periods. Polled analysis of ROSC varied and amounted to $47.4 \%$ vs. $44.0 \%$, respectively (OR: 1.36 ; 95\% CI: 0.90-2.07; $\mathrm{p}=0.15$ ).

Thirty-day mortality was observed in 1 study and was $59.8 \%$ for pre-COVID-19 period compared to $60.9 \%$ for COVID-19 period (OR: $0.95 ; 95 \% \mathrm{CI}$ : $0.75-1.22 ; \mathrm{p}=0.69$ ). In turn, overall mortality was indicated in 5 studies, and was occurring $75.8 \%$ 


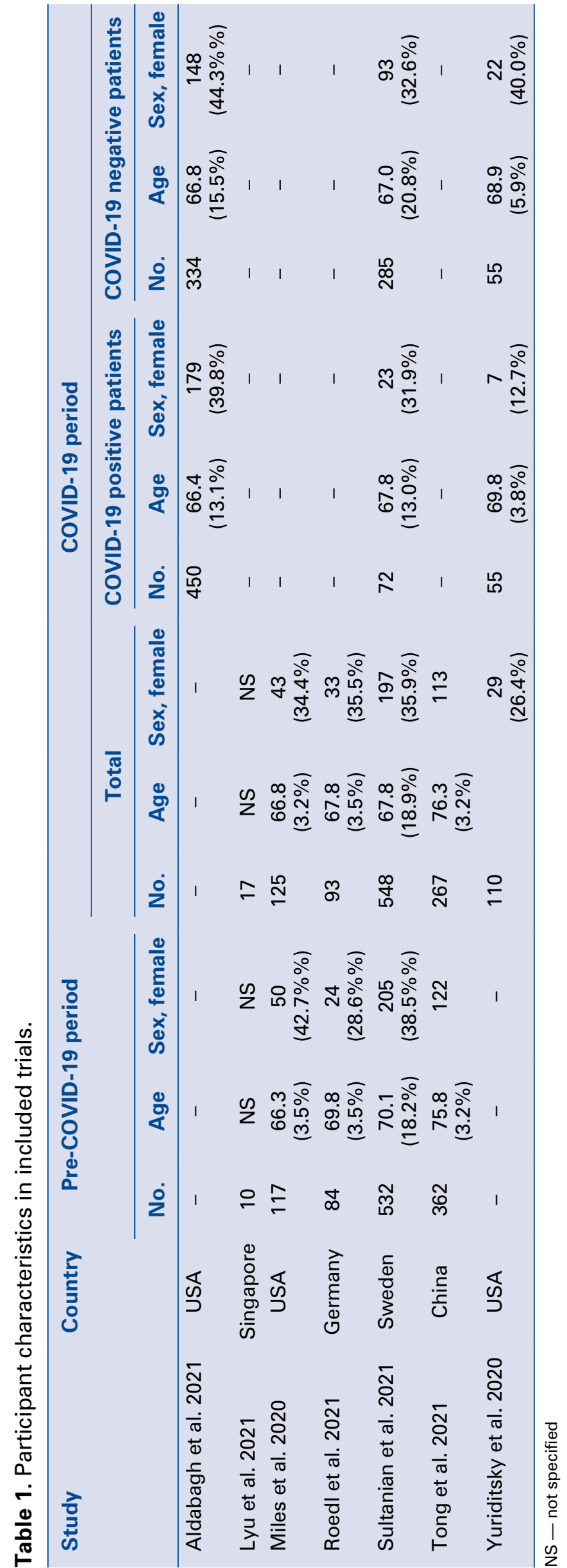

for pre-COVID-19 period compared to $74.7 \%$ for COVID-19 period (OR: 0.80; 95\% CI: $0.49-1.28$; $\mathrm{p}=0.35$ ).

\section{Analyses in SARS-CoV-2 positive vs. negative patients}

Mean age among IHCA patients with SARS$-\mathrm{CoV}-2$ positive and negative amounted to $66.9 \pm$ \pm 12.5 vs. $67.1 \pm 17.5$ years respectively (MD: $0.37 ; 95 \%$ CI: -0.93 to $1.67 ; \mathrm{p}=0.57$ ). Shockable rhythms in the group of patients with confirmed SARS-CoV-2 were observed in $9.6 \%$ of cases and it was statistically significantly lower than in the group of patients with negative results of the SARS-CoV-2 test (19.8\%; OR: $0.51 ; 95 \%$ CI: $0.35-0.73 ; \mathrm{p}<0.001)$. Detailed characteristics of the patients and the resuscitation process are presented in Table 3.

The ROSC in the SARS-CoV-2 positive patients was observed in $33.9 \%$ of IHCA cases which was statistically significantly less than with SARSCoV-2 negative patients - 52.1\% (OR: 0.47; 95\% CI: $0.30-0.73 ; \mathrm{p}<0.001)$. 30-day mortality in the case of SARS-CoV-2 positive vs. negative patients varied and amounted to $77.2 \%$ vs. $59.7 \%$ (OR: 2.08 ; 95\% CI: $1.28-3.38 ; \mathrm{p}=0.003$ ). A similar trend was observed for overall mortality, but it was not statistically significant $(94.9 \%$ vs. $76.7 \%$, respectively; OR: 3.20 ; 95\% CI: $0.98-10.49 ; \mathrm{p}=0.05)$.

\section{Discussion}

In this meta-analysis outcomes were compared of IHCA during the COVID-19 pandemic to outcomes of IHCA that happened before the SARS-CoV-2 outbreak. Depending on the study, primary outcomes were defined differently. Some considered actual survival to that predicted by the GO-FAR score which is a validated prediction model for determining survival following IHCA [33, $36,38]$. Other studies considered ROSC, which was defined as sustained ROSC or palpable pulse that lasted over $20 \mathrm{~min}$ and did not require cardiopulmonary resuscitation to be performed [38].

Contradictory to the results of our previous meta-analysis which showed no significant impact of COVID-19 pandemic to survivability ratio, most studies that we analyzed now show that the rate of survival is lower during the COVID-19 pandemic than in the pre-pandemic period. It was observed in a cohort study performed by Lyu et al. [32] that IHCA was more commonly observed during the ongoing pandemic and, what is more important, the survivability ratio in patients that underwent 


\begin{tabular}{|c|c|c|c|c|c|c|c|c|}
\hline \multirow[t]{2}{*}{ Study } & \multicolumn{8}{|c|}{ Risk of bias domains } \\
\hline & D1 & D2 & D3 & D4 & D5 & D6 & D7 & Overall \\
\hline \multicolumn{9}{|l|}{ Abdabagh 2021} \\
\hline \multicolumn{9}{|l|}{ Lyu 2021} \\
\hline \multicolumn{9}{|l|}{ Miles 2020} \\
\hline \multicolumn{9}{|l|}{ Roedl 2021} \\
\hline \multicolumn{9}{|l|}{ Sultanian 2021} \\
\hline \multicolumn{9}{|l|}{ Tong 2021} \\
\hline Yuriditsky 2020 & & & & & & & & \\
\hline
\end{tabular}

Figure 2. A summary table of review authors' judgements for each risk of bias item for each study. Domains: D1 bias due to confounding; D2 - bias due to selection of participants; D3 - bias in classification of interventions; D4 bias due to deviations from intended interventions; D5 - bias due to missing data; D6 - bias in measurement of ourcomes; D7 - bias in selection of the reported result; Judgement: $®$ Serious; $\odot$ Moderate; $\odot$ Low; ? No information.

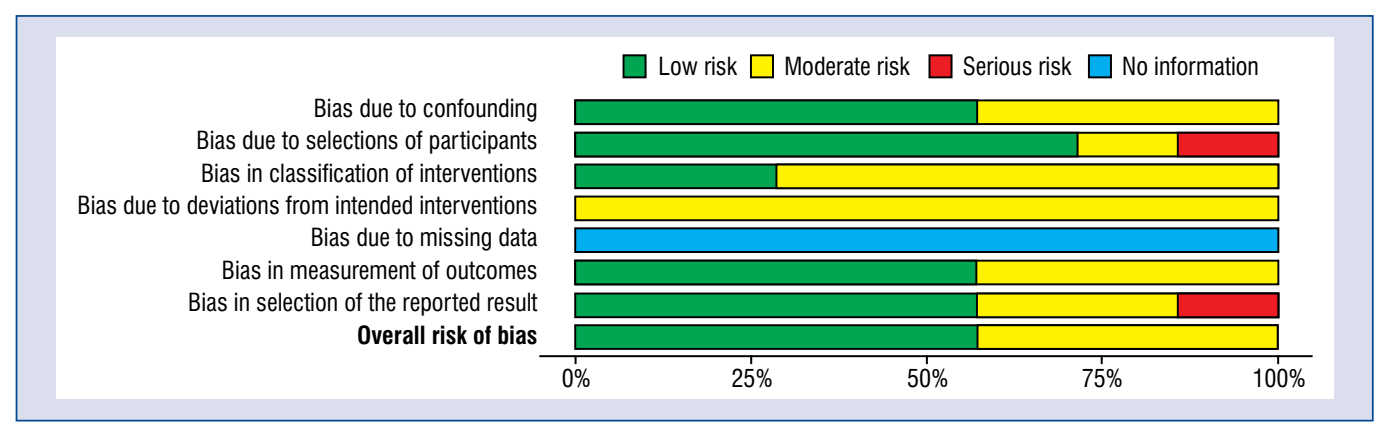

Figure 3. A plot of the distribution of review authors' judgements across randomized studies for each risk of bias item.

IHCA had decreased. This corresponds to a study performed by Miles et al. [34] in which there is statistically significant difference of survival rate of patients who suffered from IHCA during the COVID-19 pandemic and before the COVID-19 pandemic ( $3 \%$ vs. $13 \%$; $=0.007$ ). Studies that consider both OHCA and IHCA reveal that during the pandemic phase, no less than $10 \%$ of all OHCAs and $16 \%$ of IHCAs were caused by SARS-CoV-2 infection. In these cases, mortality was higher, accordingly 3.4-fold in OHCA cases, and 2.3-fold in IHCA cases.

Sometimes results were ambiguous, as in the case of Yuriditsky et al. [38] where SARS-CoV-2 infection status did not bear any significance while considering ROSC as well as 30-day survivability rate. In comparison to some earlier publications,
ROSC and 30-day survival was greater in IHCA that happened in COVID-19.

In some instances, such as in an analysis performed by Roedl et al. [35] even though the pandemic caused a decrease in number of hospital admissions, the incidence of IHCA was amplified and was occurring frequently in patients with COVID-19. Interestingly, contrary to other studies that are presented in the present meta-analysis, while compared to patients with non-COVID-19-related respiratory failure, the outcome was improved.

An interesting result comes from Tong et al. [37], which states that even after regulating for decreased comorbidity and elevated time to resuscitation team arrival, under the pandemic circumstances, ROSC in IHCA was hugely affected and its rate was considerably lower. It is worth 
Table 2. Polled analysis of in-hospital cardiac arrest (IHCA) characteristics among pre- vs. intra-coronavirus disease 2019 (COVID-19) periods.

\begin{tabular}{|c|c|c|c|c|c|c|c|c|}
\hline \multirow[t]{2}{*}{ Parameter } & \multirow[t]{2}{*}{$\begin{array}{l}\text { No. of } \\
\text { studies }\end{array}$} & \multicolumn{2}{|c|}{ Events } & \multicolumn{2}{|c|}{ Events } & \multicolumn{2}{|c|}{$\begin{array}{l}\text { Heterogeneity } \\
\text { between trials }\end{array}$} & \multirow{2}{*}{$\begin{array}{c}\text { P-value } \\
\text { for } \\
\text { differences } \\
\text { across } \\
\text { groups }\end{array}$} \\
\hline & & $\begin{array}{l}\text { Pre-COVID-19 } \\
\text { period }\end{array}$ & $\begin{array}{l}\text { COVID-19 } \\
\text { period }\end{array}$ & OR & $95 \% \mathrm{Cl}$ & P-value & $I^{2}$ statistic & \\
\hline Female sex & 4 & $36.6 \%$ & $37.4 \%$ & 0.95 & $0.68-1.32$ & 0.04 & $63 \%$ & 0.76 \\
\hline \multicolumn{9}{|l|}{ IHCA location: } \\
\hline ICU & 3 & $24.7 \%$ & $17.5 \%$ & 1.93 & $1.05-3.56$ & 0.01 & $77 \%$ & 0.03 \\
\hline ED & 2 & $12.2 \%$ & $17.1 \%$ & 0.73 & $0.42-1.27$ & 0.12 & $60 \%$ & 0.27 \\
\hline Ward & 3 & $39.0 \%$ & $40.6 \%$ & 0.58 & $0.58-2.49$ & $<0.001$ & $95 \%$ & 0.46 \\
\hline \multicolumn{9}{|l|}{ Comorbidities: } \\
\hline Hypertension & 1 & $58.3 \%$ & $74.2 \%$ & 0.49 & $0.26-0.92$ & NA & NA & 0.03 \\
\hline CAD & 2 & $25.3 \%$ & $11.1 \%$ & 2.69 & $2.00-3.63$ & 0.38 & $0 \%$ & $<0.001$ \\
\hline Diabetes & 3 & $25.6 \%$ & $16.4 \%$ & 1.51 & $0.79-2.88$ & 0.008 & $79 \%$ & 0.21 \\
\hline Cancer & 3 & $15.7 \%$ & $10.8 \%$ & 1.44 & $0.65-3.22$ & 0.004 & $82 \%$ & 0.37 \\
\hline Previous MI & 2 & $13.3 \%$ & $5.5 \%$ & 2.84 & $1.18-6.80$ & 0.28 & $13 \%$ & 0.02 \\
\hline CKD & 2 & $28.4 \%$ & $27.5 \%$ & 1.01 & $0.60-1.70$ & 0.25 & $24 \%$ & 0.96 \\
\hline \multicolumn{9}{|l|}{ Etiology: } \\
\hline $\mathrm{RI}$ & 2 & $9.7 \%$ & $19.5 \%$ & 0.31 & $0.03-3.51$ & $<0.001$ & $98 \%$ & 0.34 \\
\hline Acute MI & 2 & $17.6 \%$ & $6.4 \%$ & 3.14 & $2.16-4.56$ & 0.55 & $0 \%$ & $<0.001$ \\
\hline Acute HF & 1 & $3.4 \%$ & $2.4 \%$ & 1.44 & $0.32-6.57$ & NA & NA & 0.64 \\
\hline Stroke & 2 & $0.2 \%$ & $0.6 \%$ & 0.35 & $0.05-2.20$ & 0.99 & $0 \%$ & 0.26 \\
\hline Sepsis & 2 & $10.8 \%$ & $4.6 \%$ & 3.34 & $2.04-5.48$ & 0.77 & $0 \%$ & $<0.001$ \\
\hline Witnessed arrest & 2 & $76.0 \%$ & $75.1 \%$ & 1.13 & $0.90-1.42$ & 0.83 & $0 \%$ & 0.28 \\
\hline Shockable rhythm & 5 & $17.6 \%$ & $16.2 \%$ & 1.11 & $0.71-1.72$ & 0.10 & $48 \%$ & 0.65 \\
\hline \multicolumn{9}{|l|}{ ALS treatment: } \\
\hline Defibrillation & 2 & $32.1 \%$ & $28.9 \%$ & 0.83 & $0.29-2.35$ & 0.004 & $88 \%$ & 0.72 \\
\hline Intubation & 2 & $48.8 \%$ & $41.2 \%$ & 1.37 & $1.10-1.70$ & 0.74 & $0 \%$ & 0.005 \\
\hline MV & 3 & $61.0 \%$ & $49.1 \%$ & 1.42 & $0.82-2.45$ & 0.01 & $77 \%$ & 0.22 \\
\hline Adrenaline & 2 & $67.3 \%$ & $67.9 \%$ & 0.97 & $0.74-1.29$ & 0.31 & $3 \%$ & 0.86 \\
\hline Antiarrhythmics & 2 & $13.9 \%$ & $10.8 \%$ & 1.32 & $0.95-1.84$ & 0.88 & $0 \%$ & 0.10 \\
\hline MCC & 2 & $12.8 \%$ & $10.8 \%$ & 1.27 & $0.80-2.01$ & 0.27 & $19 \%$ & 0.31 \\
\hline TTM & 2 & $7.1 \%$ & $5.3 \%$ & 1.82 & $0.54-6.07$ & 0.04 & $76 \%$ & 0.33 \\
\hline ECPR & 1 & $6.0 \%$ & $4.3 \%$ & 1.41 & $0.37-5.43$ & NA & NA & 0.33 \\
\hline \multicolumn{9}{|l|}{ Outcomes } \\
\hline Cardiac re-arrest & 2 & $25.4 \%$ & $17.9 \%$ & 1.61 & $0.89-2.89$ & 0.23 & $32 \%$ & 0.11 \\
\hline ROSC & 5 & $47.4 \%$ & $44.0 \%$ & 1.36 & $0.90-2.07$ & 0.007 & $71 \%$ & 0.15 \\
\hline 30-day mortality & 1 & $59.8 \%$ & $60.9 \%$ & 0.95 & $0.75-1.22$ & NA & NA & 0.69 \\
\hline Overall mortality & 5 & $75.8 \%$ & $74.7 \%$ & 0.80 & $0.49-1.28$ & 0.06 & $55 \%$ & 0.69 \\
\hline
\end{tabular}

ALS - advanced life support; CAD - coronary artery disease; CKD - chronic kidney disease; CI - confidence interval; ECPR - extracorporeal cardiopulmonary resuscitation; ED — emergency department; HF — heart failure; ICU — intensive care unit; MCC — mechanical chest compression; $\mathrm{MI}$ - myocardial infarction; $\mathrm{MV}$ - mechanical ventilation; $\mathrm{NA}$ - not applicable; OR — odds ratio; RI - respiratory failure; ROSC — return of spontaneous circulation; TTM — targeted temperature management

mentioning is that even patients who were not directly suffering from SARS-CoV-2 infection were also affected by the new resuscitation practice that was implemented in IHCA cases.
According to Aldabagh et al. [33] people suffering from COVID-19 are more prone to be more seriously affected by IHCA. Even the GO-FAR score underestimates the seriousness of SARS-CoV-2 in- 
Table 3. Polled analysis of in-hospital cardiac arrest (IHCA) characteristics among severe acute respiratory syndrome coronavirus type 2 (SARS-CoV-2) positive vs. negative groups.

\begin{tabular}{|c|c|c|c|c|c|c|c|c|}
\hline \multirow[t]{2}{*}{ Parameter } & \multirow[t]{2}{*}{$\begin{array}{l}\text { No. of } \\
\text { studies }\end{array}$} & \multicolumn{2}{|c|}{ Events } & \multicolumn{2}{|c|}{ Events } & \multicolumn{2}{|c|}{$\begin{array}{l}\text { Heterogeneity } \\
\text { between trials }\end{array}$} & \multirow{2}{*}{$\begin{array}{l}\text { P-value } \\
\text { for } \\
\text { differences } \\
\text { across } \\
\text { groups }\end{array}$} \\
\hline & & $\begin{array}{l}\text { SARS-CoV-2 } \\
\text { positive }\end{array}$ & $\begin{array}{c}\text { SARS-CoV-2 } \\
\text { negative }\end{array}$ & OR & $95 \% \mathrm{Cl}$ & P-value & I’ $^{2}$ statistic & \\
\hline Female sex & 3 & $36.2 \%$ & $39.0 \%$ & 0.65 & $0.35-1.21$ & 0.02 & $73 \%$ & 0.17 \\
\hline \multicolumn{9}{|l|}{ IHCA location: } \\
\hline ICU & 3 & $36.4 \%$ & $27.4 \%$ & 1.69 & $0.62-4.56$ & $<0.001$ & $86 \%$ & 0.30 \\
\hline ED & 3 & $13.0 \%$ & $10.3 \%$ & 1.55 & $1.05-2.27$ & 0.36 & $2 \%$ & 0.03 \\
\hline Ward & 3 & $47.5 \%$ & $46.3 \%$ & 0.76 & $0.44-1.33$ & 0.04 & $70 \%$ & 0.34 \\
\hline \multicolumn{9}{|l|}{ Comorbidities: } \\
\hline Hypertension & 2 & $75.0 \%$ & $69.2 \%$ & 1.33 & $0.99-1.79$ & 0.76 & $0 \%$ & 0.06 \\
\hline CAD & 3 & $19.2 \%$ & $27.7 \%$ & 0.34 & $0.14-0.84$ & 0.008 & $79 \%$ & 0.02 \\
\hline Diabetes & 3 & $49.9 \%$ & $26.6 \%$ & 1.40 & $0.67-2.90$ & 0.01 & $78 \%$ & 0.37 \\
\hline Cancer & 2 & $4.7 \%$ & $7.4 \%$ & 0.40 & $0.03-5.50$ & 0.02 & $80 \%$ & 0.50 \\
\hline Previous MI & 1 & $1.4 \%$ & $7.0 \%$ & 0.58 & $0.17-1.99$ & NA & NA & 0.38 \\
\hline CKD & 1 & $9.1 \%$ & $30.9 \%$ & 0.22 & $0.08-0.66$ & NA & NA & 0.007 \\
\hline \multicolumn{9}{|l|}{ Etiology: } \\
\hline RI & 1 & $12.5 \%$ & $5.3 \%$ & 2.57 & $1.08-6.14$ & NA & NA & 0.03 \\
\hline Acute MI & 2 & $1.4 \%$ & $8.2 \%$ & 0.16 & $0.04-0.65$ & 0.97 & $0 \%$ & 0.01 \\
\hline Stroke & 1 & $1.4 \%$ & $0.8 \%$ & 1.99 & $0.18-22.29$ & NA & NA & 0.58 \\
\hline Sepsis & 1 & $0.0 \%$ & $1.4 \%$ & 0.43 & $0.02-8.10$ & NA & NA & 0.57 \\
\hline Witnessed arrest & 1 & $76.4 \%$ & $82.8 \%$ & 0.67 & $0.36-1.25$ & NA & NA & 0.21 \\
\hline Shockable rhythm & 3 & $9.6 \%$ & $19.8 \%$ & 0.51 & $0.35-0.73$ & 0.62 & $0 \%$ & $<0.001$ \\
\hline \multicolumn{9}{|l|}{ ALS treatment: } \\
\hline Defibrillation & 1 & $20.8 \%$ & $30.2 \%$ & 0.61 & $0.33-1.13$ & NA & NA & 0.12 \\
\hline Intubation & 1 & $48.6 \%$ & $39.6 \%$ & 1.44 & $0.86-2.42$ & NA & NA & 0.17 \\
\hline MV & 1 & $27.8 \%$ & $49.1 \%$ & 0.40 & $0.23-0.70$ & NA & NA & 0.001 \\
\hline Adrenaline & 1 & $68.1 \%$ & $61.8 \%$ & 1.32 & $0.76-2.29$ & NA & NA & 0.32 \\
\hline Antiarrhythmics & 1 & $8.3 \%$ & $11.9 \%$ & 0.67 & $0.27-1.67$ & NA & NA & 0.39 \\
\hline MCC & 1 & $8.3 \%$ & $11.6 \%$ & 0.69 & $0.28-1.73$ & NA & NA & 0.43 \\
\hline TTM & 1 & $0.0 \%$ & $1.1 \%$ & 0.56 & $0.03-10.90$ & NA & NA & 0.70 \\
\hline \multicolumn{9}{|l|}{ Outcomes } \\
\hline ROSC & 2 & $33.9 \%$ & $52.1 \%$ & 0.47 & $0.30-0.73$ & 0.32 & $1 \%$ & $<0.001$ \\
\hline 30-day mortality & 2 & $77.2 \%$ & $59.7 \%$ & 2.08 & $1.28-3.38$ & 0.85 & $0 \%$ & 0.003 \\
\hline Overall mortality & 3 & $94.9 \%$ & $76.7 \%$ & 3.20 & $0.98-10.49$ & 0.02 & $73 \%$ & 0.05 \\
\hline
\end{tabular}

ALS - advanced life support; CAD - coronary artery disease; CKD — chronic kidney disease; Cl - confidence interval; ED — emergency department; ICU — Intensive Care Unit; MCC - mechanical chest compression; MI — myocardial infarction; MV — mechanical ventilation; $\mathrm{NA}$ - not applicable; OR — odds ratio; RI — respiratory failure; ROSC — return of spontaneous circulation; TTM — targeted temperature management

fection and the rate of survival to hospital discharge is remarkably lower than in non-COVID-19 patients. In the current article, it is suggested that all these findings might be reasonably helpful in educating patients as well as healthcare professionals about risk factors that coincide with SARS-CoV-2 infection and may be useful in establishing new standards of treatment and the setting of code status designation.

\section{Limitations of the study}

There are several limitations to this review. Firstly, there is the small number of studies included in the meta-analysis, however, compared to the author's previous study, the number of patients included in the analysis was increased from 1,609 to 3,049 IHCA patients. The second limitation is the fact that in 4 studies, the authors truthfully point 
to IHCA data during the COVID-19 period, but do not classify these patients as SARS-CoV-2 positive and negative patients [32, 34, 35, 37].

\section{Conclusions}

In conclusion, in pre- vs. intra-COVID-19 periods no statistical difference was observed in ROSC, 30-day or overall mortality rate. However, during the COVID-19 pandemic, a positive SARS-CoV-2 result was associated with a lower incidence of ROSC and a higher 30-day mortality rate compared to SARS-CoV-2 negative patients.

\section{Acknowledgments}

The study was supported by the ERC Research Net and by the Polish Society of Disaster Medicine.

\section{Conflict of interest: None declared}

\section{References}

1. Rodriguez-Morales AJ, Bonilla-Aldana DK, Balbin-Ramon GJ, et al. History is repeating itself: Probable zoonotic spillover as the cause of the 2019 novel Coronavirus Epidemic. Infez Med. 2020; 28(1): 3-5, indexed in Pubmed: 32009128.

2. Dzieciatkowski T, Szarpak L, Filipiak KJ, et al. COVID-19 challenge for modern medicine. Cardiol J. 2020; 27(2): 175-183, doi: 10.5603/CJ.a2020.0055, indexed in Pubmed: 32286679.

3. Attila K, Ludwin K, Evrin T, et al. The impact of COVID-19 on airway management in prehospital resuscitation. Dis Emerg Med J. 2020; 5(4): 216-217, doi: 10.5603/demj.a2020.0047.

4. Dong E, Du H, Gardner L. An interactive web-based dashboard to track COVID-19 in real time. Lancet Infect Dis. 2020; 20(5): 533-534, doi: 10.1016/S1473-3099(20)30120-1, indexed in Pubmed: 32087114.

5. Stokes EK, Zambrano LD, Anderson KN, et al. Coronavirus Disease 2019 Case Surveillance — United States, January 22-May 30, 2020. MMWR Morb Mortal Wkly Rep. 2020; 69(24): 759-765, doi: 10.15585/mmwr.mm6924e2, indexed in Pubmed: 32555134.

6. Li G, Saguner A, An J, et al. Cardiovascular disease during the COVID-19 pandemic: Think ahead, protect hearts, reduce mortality. Cardiol J. 2020; 27(5): 616-624, doi: 10.5603/cj.a2020.0101, indexed in Pubmed: 32789839.

7. Kulak K, Wieczorek K, Krupski A, et al. SARS-CoV-2 as a real threat for healthcare workers. Dis Emerg Med J. 2020, doi: 10.5603/demj.a2020.0018.

8. Yang X, Yu Y, Xu J, et al. Clinical course and outcomes of critically ill patients with SARS-CoV-2 pneumonia in Wuhan, China: a single-centered, retrospective, observational study. Lancet Respir Med. 2020; 8(5): 475-481, doi: 10.1016/S2213-2600(20)30079-5, indexed in Pubmed: 32105632.

9. Ruetzler K, Szarpak L, Filipiak K, et al. The COVID-19 pandemic - a view of the current state of the problem. Dis Emerg Med J. 2020, doi: 10.5603/demj.a2020.0015.

10. Kowalik MM, Trzonkowski P, Łasińska-Kowara M, et al. COVID-19 - Toward a comprehensive understanding of the disease. Cardiol J. 2020; 27(2): 99-114, doi: 10.5603/CJ.a2020.0065, indexed in Pubmed: 32378729.
11. Tajbakhsh A, Gheibi Hayat SM, Taghizadeh H, et al. COVID-19 and cardiac injury: clinical manifestations, biomarkers, mechanisms, diagnosis, treatment, and follow up. Expert Rev Anti Infect Ther. 2021; 19(3): 345-357, doi: 10.1080/14787210.2020.1822737, indexed in Pubmed: 32921216.

12. Wańha W, Wybraniec M, Kapłon-Cieślicka A, et al. Myocardial infarction in the shadow of COVID-19. Cardiol J. 2020; 27(5): 478-480, doi: 10.5603/CJ.2020.0152, indexed in Pubmed: 33165896.

13. Sip M, Puslecki M, Dabrowski M, et al. Implementation of extended cardiopulmonary resuscitation procedure in in-hospital cardiac arrest: a preliminary simulated study. Dis Emerg Med J. 2021; 6(1): 10-20, doi: 10.5603/demj.a2021.0002.

14. Lorente-Ros A, Monteagudo Ruiz JM, Rincón LM, et al. Myocardial injury determination improves risk stratification and predicts mortality in COVID-19 patients. Cardiol J. 2020; 27(5): 489-496, doi: 10.5603/CJ.a2020.0089, indexed in Pubmed: 32589258.

15. Fan L, Jiang S, Yang X, et al. COVID-19 drug treatment in China. Curr Pharmacol Rep. 2020 [Epub ahead of print]: 1-9, doi: 10.1007/s40495-020-00218-5, indexed in Pubmed: 32837851.

16. Khuroo MS, Khuroo M, Khuroo MS, et al. COVID-19 vaccines: a race against time in the middle of death and devastation! J Clin Exp Hepatol. 2020; 10(6): 610-621, doi: 10.1016/j. jceh.2020.06.003, indexed in Pubmed: 32837093.

17. Gozhenko A, Szrpk L, Jguszewski MJ. COVID-19 vccine - third dose, booster dose? Wht is it nd is it necessry? Dis Emerg Med J. 2021, doi: 10.5603/DEMJ.a2021.0027.

18. Shao F, Xu S, Ma X, et al. In-hospital cardiac arrest outcomes among patients with COVID-19 pneumonia in Wuhan, China. Resuscitation. 2020; 151: 18-23, doi: 10.1016/j.resuscitation.2020.04.005, indexed in Pubmed: 32283117.

19. Armstrong RA, Kane AD, Kursumovic E, et al. Mortality in patients admitted to intensive care with COVID-19: an updated systematic review and meta-analysis of observational studies. Anaesthesia. 2021; 76(4): 537-548, doi: 10.1111/anae.15425, indexed in Pubmed: 33525063.

20. Szarpak L, Borkowska M, Peacock FW, et al. Characteristics and outcomes of in-hospital cardiac arrest in COVID-19. A systematic review and meta-analysis. Cardiol J. 2021; 28(4): 503-508, doi: 10.5603/CJ.a2021.0043, indexed in Pubmed: 33942278.

21. Borkowska MJ, Smereka J, Safiejko K, et al. Out-of-hospital cardiac arrest treated by emergency medical service teams during COVID-19 pandemic: A retrospective cohort study. Cardiol J. 2021; 28(1): 15-22, doi: 10.5603/CJ.a2020.0135, indexed in Pubmed: 33140396 .

22. Lim D, Park SYi, Choi B, et al. The comparison of emergency medical service responses to and outcomes of out-of-hospital cardiac arrest before and during the COVID-19 pandemic in an area of Korea. J Korean Med Sci. 2021; 36(36): e255, doi: 10.3346/jkms.2021.36.e255, indexed in Pubmed: 34519188.

23. Ludwin K, Bialka S, Czyzewski L, et al. Video laryngoscopy for endotracheal intubation of adult patients with suspected/ confirmed COVID-19. A systematic review and meta-analysis of randomized controlled trials. Dis Emerg Med J. 2020, doi: 10.5603/demj.a2020.0023.

24. Szarpak L, Ruetzler K, Dabrowski M, et al. Dilemmas in resuscitation of COVID-19 patients based on current evidence. Cardiol J. 2020; 27(3): 327-328, doi: 10.5603/CJ.a2020.0066, indexed in Pubmed: 32419130 .

25. Małysz M, Smereka J, Jaguszewski M, et al. An optimal chest compression technique using personal protective equipment during resuscitation in the COVID-19 pandemic: a randomized 
crossover simulation study. Kardiol Pol. 2020; 78(12): 1254-1261, doi: 10.33963/KP.15643, indexed in Pubmed: 33047942.

26. Malysz M, Dabrowski M, Böttiger BW, et al. Resuscitation of the patient with suspected/confirmed COVID-19 when wearing personal protective equipment: A randomized multicenter crossover simulation trial. Cardiol J. 2020; 27(5): 497-506, doi: 10.5603/ CJ.a2020.0068, indexed in Pubmed: 32419128.

27. Malysz M, Jaguszewski M, Szarpak L, et al. Comparison of different chest compression positions for use while wearing CBRN-PPE: a randomized crossover simulation trial. Dis Emerg Med J. 2020, doi: 10.5603/demj.a2020.0034.

28. Bhatnagar A, Khraishah H, Lee J, et al. Rapid implementation of a mechanical chest compression device for in-hospital cardiac arrest during the COVID-19 pandemic. Resuscitation. 2020; 156: 4-5, doi: 10.1016/j.resuscitation.2020.08.122, indexed in Pubmed: 32866550 .

29. Page MJ, McKenzie JE, Bossuyt PM, et al. PRISMA 2020 explanation and elaboration: updated guidance and exemplars for reporting systematic reviews. BMJ. 2021; 372: n160, doi: 10.1136/ bmj.n160, indexed in Pubmed: 33781993.

30. Hozo SP, Djulbegovic B, Hozo I. Estimating the mean and variance from the median, range, and the size of a sample. BMC Med Res Methodol. 2005; 5: 13, doi: 10.1186/1471-2288-5-13, indexed in Pubmed: 15840177.

31. Ades AE, Lu G, Higgins J. The interpretation of random-effects meta-analysis in decision models. Med Decis Making. 2016; 25(6): 646-654, doi: 10.1177/0272989x05282643, indexed in Pubmed: 16282215.

32. Lyu T, Khan F, Sajeed S, et al. In-hospital cardiac arrest incidence and outcomes in the era of COVID-19: an observational study in a Singapore hospital. Int J Emerg Med. 2021; 14(1): 33, doi: 10.1186/s12245-021-00356-7, indexed in Pubmed: 34058983.

33. Aldabagh M, Wagle S, Cesa M, et al. Survival of in-hospital cardiac arrest in COVID-19 infected patients. Healthcare (Basel). 2021; 9(10), doi: 10.3390/healthcare9101315, indexed in Pubmed: 34682995.

34. Miles JA, Mejia M, Rios S, et al. Characteristics and outcomes of in-hospital cardiac arrest events during the COVID-19 pandemic: a single-center experience from a new york city public hospital. Circ Cardiovasc Qual Outcomes. 2020; 13(11): e007303, doi: 10.1161/ CIRCOUTCOMES.120.007303, indexed in Pubmed: 32975134.

35. Roedl K, Söffker G, Fischer D, et al. Effects of COVID-19 on in-hospital cardiac arrest: incidence, causes, and outcome a retrospective cohort study. Scand J Trauma Resusc Emerg Med. 2021; 29(1): 30, doi: 10.1186/s13049-021-00846-w, indexed in Pubmed: 33557923.

36. Sultanian P, Lundgren P, Strömsöe A, et al. Cardiac arrest in COVID-19: characteristics and outcomes of in- and out-of-hospital cardiac arrest. A report from the Swedish Registry for Cardiopulmonary Resuscitation. Eur Heart J. 2021; 42(11): 1094-1106, doi: 10.1093/eurheartj/ehaa1067, indexed in Pubmed: 33543259.

37. Tong SKi, Ling L, Zhang JZ, et al. Effect of the COVID-19 pandemic on cardiac arrest resuscitation practices and outcomes in non-COVID-19 patients. J Intensive Care. 2021; 9(1): 55, doi: 10.1186/s40560-021-00570-8, indexed in Pubmed: 34507622.

38. Yuriditsky E, Mitchell OJL, Brosnahan SB, et al. Clinical characteristics and outcomes of in-hospital cardiac arrest among patients with and without COVID-19. Resusc Plus. 2020; 4: 100054, doi: 10.1016/j.resplu.2020.100054, indexed in Pubmed: 33403368. 